\title{
Ocular safety of sildenafil citrate when administered chronically for pulmonary arterial hypertension: results from phase III, randomised, double masked, placebo controlled trial and open label extension
}

\author{
(c) $\frac{(1)(8)}{\text { gy }}$ OPEN ACCESS
}

\author{
Barbara M Wirostko clinical adjunct associate professor ${ }^{1}$, Charles Tressler senior director ${ }^{2}$, Lie-Ju \\ Hwang director ${ }^{3}$, Gary Burgess senior director ${ }^{4}$, Alan M Laties professor ${ }^{5}$
}

'University of Utah, Moran Eye Center, 65 Mario Capecchi Drive, Salt Lake City, UT 84132, USA; ${ }^{2}$ SSRM Neuroscience and Pain, Pfizer Inc, New York, NY 10017, USA; ${ }^{3}$ Ophthalmology, Pfizer Inc, New York; ${ }^{4}$ Asia R\&D, Pfizer UK, Sandwich CT13 9AH, UK; ${ }^{5}$ Department of Ophthalmology, Scheie Eye Institute, University of Pennsylvania School of Medicine, Philadelphia, PA 19104, USA

\begin{abstract}
Objective To assess the ocular effects and safety profile of chronic sildenafil oral dosing in patients with pulmonary arterial hypertension.

Design 12 week, double masked, randomised, placebo controlled, phase III trial with open label extension.

Setting 53 institutions worldwide.

Participants 277 adults with idiopathic pulmonary arterial hypertension or pulmonary arterial hypertension associated with connective tissue disease or after congenital heart disease repair (mean pulmonary artery pressure $\geq 25 \mathrm{~mm} \mathrm{Hg}$; pulmonary capillary wedge pressure $\leq 15 \mathrm{~mm} \mathrm{Hg}$ at rest).

Interventions During the double masked study, oral sildenafil $20 \mathrm{mg}$, $40 \mathrm{mg}$, or $80 \mathrm{mg}$ or placebo (1:1:1:1) three times daily for 12 weeks was added to baseline drug treatment. In the extension study, the placebo, $20 \mathrm{mg}$ and $40 \mathrm{mg}$ groups received $40 \mathrm{mg}$ three times daily titrated to 80 $\mathrm{mg}$ three times daily at week 6 . After unmasking, the dose was titrated according to clinical need.

Main outcome measure Ocular safety (ocular examinations, visual function tests, participants' reports of adverse events, and visual disturbance questionnaire completed by investigators) by treatment group at 12 weeks, 24 weeks, 18 months, and yearly.

Results Findings of the objective assessments-that is, intraocular pressure and visual function tests (visual acuity, colour vision, and visual field)—were similar across groups (20 mg, $n=69 ; 40 \mathrm{mg}, \mathrm{n}=67 ; 80 \mathrm{mg}$, $\mathrm{n}=71$; placebo, $\mathrm{n}=70$ ). No clinically significant changes occurred between baseline and 12 weeks, except for an efficacy signal in contrast sensitivity for the sildenafil $40 \mathrm{mg}$ three times daily group. In right eyes, changes in intraocular pressure from baseline to week 12 ranged from a mean of -0.5 ( $95 \%$ confidence interval -1.3 to 0.2 ) $\mathrm{mm} \mathrm{Hg}$ with placebo, -0.2 ( -0.9 to 0.5$) \mathrm{mm} \mathrm{Hg}$ with sildenafil $40 \mathrm{mg}$, and -0.1 ( -0.7 to 0.5$) \mathrm{mm}$
\end{abstract}

$\mathrm{Hg}$ with $80 \mathrm{mg}$ to 0.3 (-0.4 to 0.9$) \mathrm{mm} \mathrm{Hg}$ with sildenafil $20 \mathrm{mg}$ (the approved dose for pulmonary arterial hypertension). Mean changes from baseline to week 12 in contrast sensitivity in right eyes were -0.02 (SD 0.12 ) in the sildenafil $20 \mathrm{mg}$ three times daily group compared with -0.05 $(0.18)$ in the placebo group $(P=0.044)$. Percentages of participants with deterioration in visual acuity (Snellen) from baseline to week 12 ranged from $10 \%(n=7)$ in the placebo group to $3 \%(n=2)$ in the sildenafil $20 \mathrm{mg}$ three times daily group; the same percentages had visual field changes from normal to abnormal during the period in these two groups. The investigators did not deem any findings on colour vision assessment to be clinically significant. Findings of the objective assessments in the 40 $\mathrm{mg}$ and $80 \mathrm{mg}$ three times daily sildenafil treatment groups and in left eyes were not substantially different, nor were any measures different throughout the open label extension compared with week 12. However, objective data were limited after month 18 , as most participants had missing data or visual parameters were no longer collected by investigators. Incidence of ocular adverse events reported on the case report forms and assessed by the investigator was low with all doses, but a modest, dose related incidence of chromatopsia, cyanopsia, photophobia, and visual disturbance was reported with $80 \mathrm{mg}$ three times daily consistent with the indicated dosing for erectile dysfunction. Retinal haemorrhages, captured on funduscopy, occurred in $2 \%$ (4/207) of sildenafil treated participants and none in the placebo group during the double masked study and in $4 \%$ (10/259) during the open label extension.

Conclusions Sildenafil dosing up to $80 \mathrm{mg}$ three times daily is safe and well tolerated from an ocular perspective in patients with pulmonary arterial hypertension. Daily chronic dosing in this patient population was not associated with visual change and had no detrimental effect on best corrected visual acuity, contrast sensitivity, colour vision, or visual field, or on slit lamp examinations, funduscopy, or intraocular pressure during the duration of this study. 
Trial registration Clinical trials NCT00644605 and NCT00159887.

\section{Introduction}

Orally administered selective phosphodiesterase type 5 inhibitors developed for the management of erectile dysfunction have been used more recently as a treatment for pulmonary arterial hypertension. Sildenafil citrate (Revatio, Pfizer Inc, New York) is approved in several countries worldwide, including the United States and Europe, for this indication. This class of vasodilators is capable of crossing the blood-retina barrier. ${ }^{1}$

Phosphodiesterases produce vasoconstriction of smooth muscle cells through their ability to degrade cyclic nucleotides such as cyclic guanosine monophosphate. As nitric oxide acts to increase concentrations of cyclic guanosine monophosphate through stimulation of guanylate cyclise, ${ }^{2}{ }^{3}$ and phosphodiesterase type 5 hydrolyses cyclic guanosine monophosphate, the combined effect of these changes is a significant lowering of cyclic guanosine monophosphate concentrations. ${ }^{14}$ Downstream effects of this reduction in cyclic guanosine monophosphate through phosphodiesterase type 5 activation include increases in intracellular calcium and potassium leading to vasoconstriction and the promotion of vascular smooth muscle cell proliferation and vascular fibrosis. ${ }^{5-7}$ By increasing cyclic guanosine monophosphate concentrations, phosphodiesterase type 5 inhibitors promote systemic arterial smooth muscle relaxation and vasodilatation while simultaneously preventing cellular proliferation; they thus offer the possibility of alleviating pulmonary arterial hypertension. ${ }^{6}$

Pulmonary arterial hypertension is characterised by restricted flow through the pulmonary circulation with resultant increase in pulmonary vascular resistance and, ultimately, right heart failure. ${ }^{8}$ Although the underlying pathophysiology is not completely understood, the key features are the decreased expression of nitric oxide synthase by endothelial cells together with increased expression of phosphodiesterase type 5 in smooth muscle cells of the pulmonary artery and right ventricular myocardium. ${ }^{5}{ }^{\text {9-12 }}$

Owing to the widespread use of single dose sildenafil as a treatment for erectile dysfunction, clinical studies and case reports have focused on the possible systemic and ocular side effects (including those on visual function) associated with sildenafil and other phosphodiesterase type 5 inhibitors (for recent reviews, see Laties $2009^{1}$ and Kerr and Danesh-Meyer $2009^{4}$ ). Phosphodiesterase type 5 is expressed on the retinal and choroidal vasculature (smooth muscle and endothelial cells) as well as on ganglion and bipolar cells. Concerns have been raised about potential ocular side effects of sildenafil that derive directly from its effect on ocular vasculature and from its concurrent crossover inhibition of phosphodiesterase type 6 , which is expressed in the retinal photoreceptor layer (both rods and cones), ${ }^{13}$ with a potency approximately 10 -fold less than that for phosphodiesterase type $5 .{ }^{13}{ }^{14}$ The most common visual disturbance reported is a dose dependent reversible impairment of colour discrimination, principally in the blue-green to blue-purple range. ${ }^{1516}$ Transient electroretinographic changes have been reported with sildenafil, including increases in light sensitivity, ${ }^{17}{ }^{18}$ possibly reflecting inhibition of phosphodiesterase type $6,{ }^{4}$ but no other effects on psychophysical measures of visual function have been found. ${ }^{419} \mathrm{~A}$ recent study in sheep showed increased intraocular pressure within one hour of a dose $^{20}$; however, in humans, clinically important adverse effects of sildenafil on intraocular pressure have not been reported..$^{21-23}$

Studies of the effects of sildenafil on ocular vasculature have not had consistent results. Several reports show little or no effect on various measures related to vessel diameter and ocular circulation. ${ }^{24-27}$ By contrast, other studies have measured increases in one or both of these vascular properties after oral intermittent sildenafil treatment. ${ }^{1328-33}$ The inconsistencies among these study results may reflect variations in experimental approaches, instrumentation, and length of dosing as well as the short lived and relatively modest amplitude of the changes measured. ${ }^{19}$ Rare vascular events that have been reported in case studies include non-arteritic anterior ischaemic optic neuropathy, ${ }^{1}$ central serous chorioretinopathy, ${ }^{34}$ branch retinal artery occlusions, ${ }^{35}$ and third nerve palsy. ${ }^{37} 38$

To evaluate potential effects on visual function and the ocular safety profile of sildenafil during chronic oral use, the pivotal placebo controlled trial of sildenafil for the treatment of pulmonary arterial hypertension and its open label extension included ophthalmic examinations and assessments of visual function. During the double masked study, sildenafil doses of 20,40 , or $80 \mathrm{mg}$ or placebo were administered orally three times daily for 12 weeks. ${ }^{39}$ In the extension, doses were first up-titrated to a maximum of $80 \mathrm{mg}$ three times daily at week 6 in a masked fashion while the $80 \mathrm{mg}$ group had sham titration. After the last participant in the double masked study had completed 12 weeks of treatment, doses in the extension study were unmasked and then could be adjusted according to clinical need to a maximum of $80 \mathrm{mg}$ three times daily or a minimum of $20 \mathrm{mg}$ three times daily. We report here the ocular findings.

\section{Methods}

The initial 12 week, double masked, placebo controlled study of sildenafil citrate for pulmonary arterial hypertension was conducted in 53 centres in Australia, Belgium, Brazil, Canada, the Czech Republic, Denmark, France, Germany, Hong Kong, Hungary, Ireland, Israel, Italy, Mexico, the Netherlands, Norway, the Philippines, Poland, Singapore, South Africa, South Korea, Spain, Sweden, the United Kingdom, and the United States between October 2002 and November 2003

(NCT00644605). Participants who completed the double masked study could enrol in an open label, optimised dose extension study (NCT00159887). All participants gave written informed consent. Sildenafil has been widely prescribed since it was introduced into the market in 2005 , and recent data indicate that sildenafil $20 \mathrm{mg}$ three times daily has more than 118000 patient years of experience globally

The methods and primary results of both the double masked study and the extension have been reported. ${ }^{39}$ A summary of the methods and details of the ophthalmologic assessments follows.

Adult participants with pulmonary arterial hypertension, defined as a mean pulmonary artery pressure of at least $25 \mathrm{~mm} \mathrm{Hg}$ and a pulmonary capillary wedge pressure of $15 \mathrm{~mm} \mathrm{Hg}$ or lower at rest, were eligible. Participants could have idiopathic pulmonary arterial hypertension, pulmonary arterial hypertension associated with connective tissue disease, or pulmonary arterial hypertension following surgical repair of congenital systemic to pulmonary shunts at least five years previously. Patients with a six minute walking distance of less than $100 \mathrm{~m}$ or more than $450 \mathrm{~m}$ were excluded; intravenous epoprostenol, oral bosentan, intravenous or inhaled iloprost, or subcutaneous treprostinil, as well as supplementation with L-arginine, were prohibited. Warfarin, calcium channel blockers, digoxin, oxygen, and diuretics were allowed during the study. Entry criteria were unrelated to history of ocular pathology, macular degeneration, glaucoma, or ocular hypertension or to baseline intraocular pressure. 
At baseline, participants were randomised (1:1:1:1) to 20, 40, or $80 \mathrm{mg}$ of sildenafil or placebo administered three times daily. Participants randomised to receive $80 \mathrm{mg}$ initially received 40 $\mathrm{mg}$ for one week and then were titrated to $80 \mathrm{mg}$. All other participants had a sham titration. Study drug was added to the participant's baseline drug treatment regimen and administered for 12 weeks.

The study used an automated interactive voice response system incorporating a central randomisation and drug supply scheme. The randomisation scheme was stratified by baseline walking distance $(<325 \mathrm{~m}, \geq 325 \mathrm{~m})$ and cause (primary pulmonary arterial hypertension, pulmonary hypertension secondary to connective tissue disease, pulmonary hypertension with surgical repair). The interactive voice response system assigned numbers sequentially to the participants from the appropriate randomisation stratification group as they were determined to be eligible for treatment by the investigator. The drug supply scheme consisted of a list of pack numbers and corresponding treatment types. A unique pack number identified each drug pack. The interactive voice response system assigned participants a pack number from the list corresponding to the treatment assigned. At the start of the masked study, the study site was instructed on the method for unmasking, which was either a manual or an electronic process. Masking codes were broken only in emergency situations for reasons of participants' safety. The investigator was encouraged to contact the study sponsor before unmasking. When the code was broken, the reason was fully documented and entered on the study report form.

In the open label extension, the first pivotal portion involved a forced masked upward titration (figure $\downarrow$ ). The participants originally randomised to receive placebo or sildenafil 20 or 40 $\mathrm{mg}$ in the double masked study received a starting dose of sildenafil $40 \mathrm{mg}$ three times daily during the first six weeks, after which the dose was increased to $80 \mathrm{mg}$ three times daily. Those randomised to $80 \mathrm{mg}$ sildenafil three times daily in the double masked study remained on this dose for the first six weeks of the extension and had a sham dose escalation. One down-titration was permitted for tolerability during the first 12 weeks of the extension study. The open label extension study was unmasked after the last participant had completed at least three months of extension treatment. After unmasking, sildenafil was titrated according to clinical need as determined by the investigator and the participant to a maximum of $80 \mathrm{mg}$ three times daily or to a minimum of $20 \mathrm{mg}$ three times daily. Participants were to continue taking their optimised dose of sildenafil until the last enrolled patient had completed three years of treatment or until sildenafil was shown to be ineffective, poorly tolerated, or unsafe in the treatment of pulmonary arterial hypertension.

All doses were to be administered at least six hours apart. Participants were asked to record doses taken in their diary cards and took the first dose in the morning at the hospital at baseline and weeks 8 and 12. Participants were asked to return unused drug at each visit and were given sufficient supply for treatment until the next visit.

During the initial double masked portion of the study, ophthalmologists did ophthalmic examinations and visual function tests in both eyes at baseline and week 12. The ophthalmic examinations included external inspection of the eye, slit lamp biomicroscopy of the anterior portion, funduscopy to examine the posterior segment, and measurement of intraocular pressure by Goldmann applanation tonometry. Visual function was evaluated with best corrected visual acuity testing using a Snellen eye chart, the Farnsworth-Munsell D15 hue test for colour, the Pelli-Robson test of contrast sensitivity, and the Humphrey visual field test. The timing of ocular examinations and assessments in relation to administration of oral sildenafil, diurnal intraocular pressure variability, or both was not pre-specified. Intraocular pressure changes of less than $4 \mathrm{~mm}$ $\mathrm{Hg}$ from baseline to week 12 were predefined as being clinically not significant. Investigators recorded all observed and volunteered adverse events, the severity (mild, moderate, or severe) of the events, and their opinion of the relation of the events to study treatment on case report forms. We coded adverse events centrally using the Medical Dictionary for Regulatory Activities. In addition, the investigator completed a four item visual disturbances safety questionnaire if a participant reported an ocular adverse event. The questionnaire included items reflecting the timing, duration, and impact of the event; most responses were recorded in check boxes, but the instrument also included an open ended question on the effect of the symptom on the participant's day to day life. In the open label portion of the extension study, once all participants had completed their first 12 weeks, the same ocular examinations including slit lamp, funduscopy, intraocular pressure, and visual function measurements were done in both eyes at week 12 (corresponding to week 24 of the overall trial), month 15 (corresponding to month 18 of the overall trial), and yearly thereafter. At the baseline visit, testing was done before the initial dose of sildenafil was administered, whereas evaluations at subsequent visits were done after the dose.

We summarised the results of the visual function assessments and the visual disturbance questionnaire by randomised treatment group. We did not analyse between group differences with statistical hypothesis testing owing to low power. Ocular adverse event data collected by the investigator and reported on the case report form are summarised per number (percentage) of participants and not per eye. For intraocular pressure and visual function assessments (such as visual acuity and contrast sensitivity), we report data for the right eye unless results for the left eye seemed to be clinically significantly different.

\section{Results}

In all, 278 participants were randomly assigned to receive sildenafil in doses of $20 \mathrm{mg}(\mathrm{n}=69), 40 \mathrm{mg}(\mathrm{n}=68)$, or $80 \mathrm{mg}$ $(n=71)$ or to receive placebo $(n=70)$, and 277 participants took at least one dose of study drug. A total of 265 participants completed the 12 week randomised study, and 259 entered the extension. The median length of treatment during the extension was 1171 (range 1-1442) days, and 222 participants completed one year of treatment with sildenafil monotherapy. ${ }^{39}$ However, data reflecting the results of the visual function assessments after month 18 were limited given that most participants had data missing or the visual parameters were no longer collected by investigators. Subjective adverse event data (that is, reports by participants) were collected throughout the double masked and open label studies.

Baseline characteristics were similar across treatment groups (table $1 \Downarrow$ ). About three quarters of participants were female, and the overall mean age was approximately 49 years. Between $60 \%$ and $65 \%$ of participants in each group were diagnosed as having idiopathic pulmonary arterial hypertension, and $58 \%$ overall were classified as World Health Organization functional class III. Only six participants had pre-existing glaucoma or ocular hypertension. Across treatment groups, the mean baseline intraocular pressure was approximately $15 \mathrm{~mm} \mathrm{Hg}$, and $71 \%$ of participants had normal visual fields at baseline as assessed by clinical investigators. 
At baseline ophthalmic examinations, the most prevalent ocular finding reported was dilated episcleral vessels (right eye: 44/260, $17 \%$; table $2 \Downarrow$ ). Conjunctival injection and abnormal blood vessels were also relatively common, with incidences of $13 \%$ (34/260) and 12\% (32/260). Retinal vein engorgement and conjunctival oedema were relatively rare at baseline. The baseline incidence of dilated episcleral blood vessels, conjunctival injection, and abnormal blood vessels was somewhat higher in participants with primary pulmonary arterial hypertension than in those with pulmonary arterial hypertension associated with connective tissue disease (table $2 \Downarrow$ ). For example, conjunctival injection was present in the right eye of 22/164 (13\%) participants with primary pulmonary arterial hypertension and in 7/81 (9\%) with pulmonary arterial hypertension associated with connective tissue disease. The baseline incidence of retinal vein engorgement was lower in participants taking warfarin (right eye: $2 / 114,2 \%$ ) than in those not taking warfarin (right eye: $8 / 146,6 \%$ ), whereas the incidence of dilated episcleral vessels was higher in participants taking warfarin (right eye: $21 / 114,18 \%$ ) than in those not taking warfarin (right eye: 23/146, 16\%).

\section{2 week, randomised, double masked pivotal study}

In all treatment groups, findings of the ophthalmic examinations (external inspection, slit lamp, funduscopy, and intraocular pressure) and visual function tests were little changed from baseline to week 12 in the double masked study. No clinically significant changes from baseline to week 12 in mean intraocular pressure occurred in either eye in any treatment group. In right eyes, the modest changes in intraocular pressure that did occur ranged from a mean change of $-0.5(95 \%$ confidence interval -1.3 to 0.2$) \mathrm{mm} \mathrm{Hg}$ with placebo, -0.2 ( -0.9 to 0.5$) \mathrm{mm} \mathrm{Hg}$ with sildenafil $40 \mathrm{mg}$, and -0.1 ( -0.7 to 0.5$) \mathrm{mm} \mathrm{Hg}$ with 80 $\mathrm{mg}$, to a mean change of 0.3 ( -0.4 to 0.9$) \mathrm{mm} \mathrm{Hg}$ with sildenafil $20 \mathrm{mg}$. Most participants in all groups had "clinically non-significant" changes in intraocular pressure $(<4 \mathrm{~mm} \mathrm{Hg})$ from baseline to week 12 .

We found no change in log contrast sensitivity $(<0.15)$ at week 12 relative to baseline in most participants in any treatment group (table $3 \Downarrow$ ). The percentages of participants showing deterioration in log contrast sensitivity from baseline to week 12 were similar in the $80 \mathrm{mg}$ sildenafil and placebo groups and were somewhat lower in the other sildenafil dose groups. In the right eye, the mean change from baseline to week 12 was -0.02 (SD 0.12), 0.02 (0.14), and $-0.02(0.14)$ in the sildenafil 20, 40 , and $80 \mathrm{mg}$ groups, compared with $-0.05(0.18)$ in the placebo group $(\mathrm{P}=0.044, \mathrm{P}<0.001$, and $\mathrm{P}=0.093$ versus placebo). In right eyes, proportions of responders (positive change in log contrast sensitivity $\geq 0.15$ ) in the sildenafil treatment groups compared with placebo were 5\% versus $3 \%(\mathrm{P}=0.638)$ for 20 $\mathrm{mg}$ three times daily, $12 \%$ versus $3 \%(\mathrm{P}=0.044)$ for $40 \mathrm{mg}$ three times daily, and $8 \%$ versus $3 \%(\mathrm{P}=0.222)$ for $80 \mathrm{mg}$ three times daily. In left eyes, the corresponding proportions of responders in the sildenafil treatment groups compared with placebo were $5 \%$ versus $2 \%(\mathrm{P}=0.305), 11 \%$ versus $2 \%(\mathrm{P}=0.026)$, and $5 \%$ versus $2 \%(\mathrm{P}=0.290)$.

Treatment with sildenafil for 12 weeks did not seem to alter visual acuity at any dose tested. Most participants in all treatment groups showed no change or indeterminable change in the number of lines read on the Snellen chart from baseline to week 12 (table $3 \Downarrow$ ). The percentage of participants who showed an algebraic negative change from baseline in visual correction or deterioration in either eye, defined as a decrease of one or more lines read in those with a baseline assessment between 6/6 and 6/60, was also similar across groups. Most participants with normal visual fields at baseline continued to have normal visual fields at week 12 (table $4 \Downarrow$ ). We found no apparent differences among treatment groups in the overall frequency of visual field changes.

We plotted results of colour vision assessments manually for each participant. One of the authors (AML) assessed all abnormal findings and changes from baseline. We made queries to investigators for all identified adverse events, and they said that no clinically significant findings occurred. We then archived the plots.

The incidence of reported and observed ocular adverse events was low (table $5 \Downarrow$ ). Ocular adverse events that did occur were of mild to moderate severity in all cases, with the exception of one participant in the sildenafil $80 \mathrm{mg}$ group who developed severe photophobia 72 days after the start of the study. We saw a modest, dose related increase in the incidence of phosphodiesterase type 6 mediated effects consistent with the known ocular profile of single dose sildenafil for erectile dysfunction, including chromatopsia, cyanopsia, photophobia, visual brightness, and visual disturbance; the incidence of each of these effects was $7 \%$ or lower with sildenafil $80 \mathrm{mg}$ and less than 5\% with sildenafil $40 \mathrm{mg}$. For the sildenafil $20 \mathrm{mg}$ three times daily group, which received the clinically approved dose, as well as for those receiving placebo, these incidences were less than $2 \%$. Four cases of retinal haemorrhage were observed in participants receiving warfarin, one each in the sildenafil 20 $\mathrm{mg}$ and $80 \mathrm{mg}$ groups (incidence $=1 \%$ ) and two in the sildenafil $40 \mathrm{mg}$ group (incidence $=3.0 \%$ ).

Overall, the frequency of characteristic ocular anatomical findings seen in right heart failure/pulmonary arterial hypertension at baseline and at week 12 seemed not to differ among treatment groups for right eyes (table $6 \Downarrow$ ). No cases of serous retinal or choroidal detachment were observed in either eye in any treatment group at baseline, but both conditions were detected at week 12 in the left eye of one participant with pulmonary arterial hypertension associated with connective tissue disease in the sildenafil $40 \mathrm{mg}$ group (incidence for each=2\%). The upward drift in conjunctival injection was somewhat greater in participants treated with sildenafil relative to those treated with placebo; however, we found no evidence of a significant dose-response relation. We noted a modest increase in the incidence of conjunctival oedema in sildenafil treated participants between baseline and week 12, but we found no evidence of a dose-response relation. A slight increase in dilated episcleral vessels occurred in both sildenafil and placebo treated groups between baseline and week 12; the magnitude of the increase seemed similar in the active treatment and placebo groups, and the increase was not dose dependent in the sildenafil groups. The incidence of abnormal blood vessels remained fairly constant from baseline to week 12 in the placebo group as well as in all the sildenafil dose groups. The incidence of retinal vein engorgement was relatively low in all groups both at baseline and at week 12. For each of these measures, we saw a similar pattern in participants with primary pulmonary arterial hypertension and in those with pulmonary arterial hypertension associated with connective tissue disease.

\section{Open label, optimised dose extension}

Doses of $12(5 \%)$ participants were titrated downward from sildenafil $80 \mathrm{mg}$ three times daily during the first 12 weeks of open label treatment. Table $7 \Downarrow$ shows a cross tabulation of the double masked study dose groups by dose during the open label study. As in the double masked pivotal study, sildenafil 
maintained a favourable ocular safety profile throughout the open label phase of the optimised dose extension. In both eyes, we found no clinically significant changes in the results of the ophthalmic examinations and or visual function tests. At week 24 , three quarters (163/218) of participants showed no change in intraocular pressure, defined as a change of less than $4 \mathrm{~mm}$ $\mathrm{Hg}$ relative to baseline. Among those who did show a change of $4 \mathrm{~mm} \mathrm{Hg}$ or more, intraocular pressure was more likely to decrease than to increase. Likewise, findings with regard to contrast sensitivity, visual acuity, colour vision, and visual field measurements were not substantially different at week 24 compared with week 12 .

The incidence of reported and observed ocular adverse events was low. As expected, a modest incidence of phosphodiesterase type 6 mediated effects was noted at the last visit (table $8 \Downarrow$ ).

The incidence of retinal haemorrhage remained low during open label treatment, with a total of $11(4 \%)$ cases, which included three participants who were receiving warfarin. Fifty per cent of the noted ocular haemorrhages, including retinal

haemorrhages, that occurred as adverse events in participants taking warfarin were noted to have resolved at the time of each participant's last visit.

After 24 weeks and 18 months of total follow-up, the incidence of characteristic ocular anatomical findings seen in participants with right heart failure pulmonary arterial hypertension was generally similar to that noted after 12 weeks of double masked treatment. At week 24, serous retinal detachment and choroidal detachment were observed in both eyes of the participant who had shown these abnormalities in the left eye only at week 12; choroidal detachment was observed in the right eye of one additional participant. Thus, at week 24 , the incidence of serous retinal detachment was $0.4 \%$ (1/239) for both left and right eyes, and the incidence of choroidal detachment was $0.4 \%(1 / 239)$ for left eyes and $0.8 \%(2 / 239)$ for right eyes. Both conditions subsequently resolved in these two participants, and no cases of either serous retinal detachment or choroidal detachment were reported at month 18 (incidence: either eye $=0 \%$ ). The incidence of conjunctival injection was consistent across the open label extension treatment (about 17\%), and that of conjunctival oedema was low at week 12 and decreased moderately at week 24 and month 18 (right eye: 2\% (4/256), $1 \%$ (3/239), and $1 \%(1 / 117)$, respectively). The incidence of dilated episcleral blood vessels was higher at week 12 than at week 24 or month 18 (right eye: 22\% (56/256), 18\% (44/239), and $15 \%$ (17/117), respectively). The incidence of abnormal blood vessels decreased slightly from week 12 to week 24 but was similar to the baseline level at month 18 (right eye: $12 \%$ (31/256), $8 \%$ (20/239), and 13\% (15/117), respectively), whereas the incidence of retinal vein engorgement was lowest at month 18 (right eye: 6\% (15/256), 6\% (15/239), and 3\% (4/117)).

\section{Discussion}

The principal finding of both the pivotal trial and its open label extension is that chronic oral sildenafil treatment did not lead to any significant ocular safety signals on ocular examination, on assessment of visual function, or through visual disturbance questionnaires. With respect to changes in subjective visual function, the only effect was a low, dose dependent, and in many cases reversible incidence of the transient phosphodiesterase type 6 mediated effects that have been reported from clinical experience with single use sildenafil in the treatment of erectile dysfunction. ${ }^{14}$ Moreover, in the pivotal trial, treatment with the clinically approved dose, $20 \mathrm{mg}$ three times daily, resulted in a frequency of these effects that was indistinguishable from that with placebo treatment. Similarly, we found no evident adverse effect of chronic sildenafil on visual acuity or contrast sensitivity. Notably, sildenafil $40 \mathrm{mg}$ three times daily improved log contrast sensitivity compared with placebo over 12 weeks. Although it is a functional test associated with variability and noise, contrast sensitivity provides an objective measure of retinal/neuronal/photoreceptor function that can be affected by microvascular changes. ${ }^{40} 41$

In addition to having no significant effect on measures of visual function, chronic sildenafil treatment in this study was not associated with an increased incidence of reported and observed ocular adverse events, and the incidences of retinal haemorrhage, conjunctival oedema, and serous retinal and choroidal detachment were low, with no evident effect on intraocular pressure in objective ophthalmic examinations. However, the trial was not adequately powered to detect significant differences between groups for ocular events occurring at low frequency, and a true causality cannot be determined. Retinal haemorrhage is an ocular finding that has been described in patients with pulmonary arterial hypertension and in those with connective tissue disease. ${ }^{42-45}$ Risk factors for retinal haemorrhage are numerous and include sudden changes in ocular or vascular pressures, such as those that occur during vomiting, trauma, or violent exercise. They also are seen at both extremes of vascular perfusion pressure, either arterial or venous, being noted both in acute systemic hypertension and in chronic venous insufficiency. Anticoagulants, which are commonly used by patients with pulmonary arterial hypertension, are associated with an increased risk of ocular and retinal haemorrhages. In virtually all cases, responsibility lies with the risk imposed by the prolonged coagulation time brought about by warfarin treatment. Moreover, in large general population surveys, microvascular abnormalities, including small retinal haemorrhages, are consistently noted in $2-4 \%$ of people surveyed. ${ }^{46}$ Commonly, retinal haemorrhages can be incidental clinical findings that resolve without sequelae.

In this study, we also saw the low incidence of serous retinal and choroidal detachments that is implied from case reports of untreated pulmonary arterial hypertension..$^{42} 43$ 47-49 Those that occurred were most likely due to the underlying systemic pathology, possibly resulting from alterations in choroidal blood flow, such as increased choroidal pressure, venous stasis, and uveal effusions. ${ }^{50}$ Dilated episcleral veins and conjunctival injection were the most common observed ocular anatomical findings in both untreated and treated participants with pulmonary arterial hypertension in this study. With respect to the incidence of dilated episcleral vessels and retinal engorgement, these were similar in both sildenafil and placebo groups during the double masked study and actually declined during the open label extension. Whether these decreases were treatment associated effects due to changes in the ocular vascular stasis, vascular changes associated with the severity and chronicity of the underlying pulmonary arterial hypertension, ${ }^{49} 50$ or the result of attrition of participants is, however, unclear. The upward drift in the incidence of conjunctival injection in both treatment groups at 12 weeks seemed to be slightly greater in participants receiving sildenafil. However, across the 15 months of the open label extension, the incidence was consistent across treatment groups. As conjunctival oedema is a less specific ocular manifestation of pulmonary arterial hypertension, this finding is difficult to assess.

\section{Relation to other studies}

As discussed above, the findings of this study are in accord with existing reports in the literature of the short term effects of single 
use sildenafil on measures such as colour discrimination and visual sensitivity. ${ }^{419}$ Moreover, a recent study examining long term use of sildenafil in healthy people found no significant difference from placebo in such measures of visual function as visual acuity, static perimetry, or colour discrimination or in key electroretinographic variables, ${ }^{23}$ whereas a study of five patients with pulmonary arterial hypertension taking high doses, up to $225 \mathrm{mg}$ /day for one to four years, also found only modest electroretinographic changes in cone function and no evidence of serious visual toxicity. ${ }^{51}$

One visual disorder, non-arteritic anterior ischaemic optic neuropathy, has been reported as a rare event (18 instances in all) after single use sildenafil. ${ }^{1}$ Although no definitive link exists between these occurrences and the drug, the product label includes advice to discontinue use of sildenafil in the event of sudden loss of vision. ${ }^{14}$ Optic nerve heads that are relatively small with small cup to disc ratios have been reported to be at risk of non-arteritic anterior ischaemic optic neuropathy. ${ }^{52}$ Estimates of the overall incidence of non-arteritic anterior ischaemic optic neuropathy in the United States range from 2.52 to 11.8 men and from 2.14 to 9.2 women per 100000 of the population aged over $50^{53} 54$; the comparable estimate in China for adults aged over 40 is six per $100000 .{ }^{55}$ With intermittent usage of sildenafil, however, the estimated incidence of non-arteritic anterior ischaemic optic neuropathy is only 2.8 per 100000 patient years of use. ${ }^{156}$ Moreover, many of the risk factors for non-arteritic anterior ischaemic optic neuropathy, such as diabetes, hypertension, hypercholesterolaemia, atherosclerosis, ischaemic heart disease, stroke, pro-thrombotic factors, raised homocysteine concentrations, sleep apnoea, and nocturnal hypotension, are also risk factors for erectile dysfunction, ${ }^{1}$ so that assessing whether occurrences of non-arteritic anterior ischaemic optic neuropathy should be attributed to the drug or to the underlying systemic vascular pathology is difficult. Although the potential for inducing non-arteritic anterior ischaemic optic neuropathy in patients with pulmonary arterial hypertension cannot be discounted, ${ }^{57}$ on the basis of this study of chronic sildenafil use, it seems likely that in patients with similar characteristics, no increased risk of non-arteritic anterior ischaemic optic neuropathy exists for at least 18 months.

\section{Strengths and limitations}

A decision was made during the design of this double blind study and open label extension not to do electroretinographic testing for several reasons. Firstly, in preclinical studies with two species, no evidence existed of general ocular toxicity or of specific retinal structural changes with long term, high dose sildenafil administration. ${ }^{58}$ Furthermore, the results from a series of electroretinographic studies in humans receiving sildenafil are similarly reassuring, showing either no effect at all or modest, fully reversible, transient electroretinographic changes that do not translate into significant effects on visual performance. ${ }^{59-61}$ Finally, the risk of retinal toxicity seems to be exceedingly small, whereas the constraints on and limitations of clinical electroretinographic testing at multiple sites are considerable. Transportation of these seriously ill patients to certified centres for electroretinographic testing would be necessary, and the underlying systemic disease and ocular manifestations could contribute to technical difficulties with administration and interpretation of the test.

Several limitations to the study should be noted. Firstly, because ocular safety, including visual function, was not the primary objective of this phase III study, the sample size calculation was not based on ocular end points. We believe that the large amount of data available is generally sufficient for assessment of ocular safety with sildenafil use in patients with pulmonary arterial hypertension, although the power to detect rare, serious events was lacking. Other limitations were associated with the timing of the ocular assessments, the number of examinations/tests done, and the omission of diagnostic procedures such as electroretinographic and standardised digital fundus photos that would have provided additional information about vascular or optic nerve effects. For example, the fact that only one intraocular pressure measurement was taken was reasonable, but the timing of this measurement in relation to diurnal intraocular pressure variability should have been pre-specified. Also, several measurements of intraocular pressure should have been taken at each sitting (right eye, followed by left) and the mean presented. In addition, the Humphrey visual field examination has many limitations in itself, such as reproducibility, between visit variability, a lack of standardisation as to what constitutes a normal or abnormal field, the need for three examinations averaged as a baseline to assess the average mean deviation and decibel loss over time, and the occurrence of false positives and negatives which support the performance of repeat tests. Finally, findings from this study should not be extrapolated to the use of sildenafil for erectile dysfunction or for other reasons. ${ }^{62}$

\section{Conclusions}

The main purpose of the pivotal study and its open label extension was to investigate the overall efficacy and systemic safety of sildenafil in patients with pulmonary arterial hypertension during short term and long term chronic daily exposure. The ocular safety and visual function evaluation was an additional component based on newly emerging ocular safety signals with the use of sildenafil on an as needed basis for the indication of erectile dysfunction. The data show that sildenafil, taken three times daily at doses up to four times the usual recommended dose for erectile dysfunction, is not associated with compromised visual function or ocular adverse events.

This study was sponsored by Pfizer UK, Sandwich, UK. Editorial support, including contributing to the first draft of the manuscript, revising the paper on the basis of authors' feedback, and styling the paper for journal submission, was provided by Jane G Murphy of Zola Associates and was funded by Pfizer Inc, New York, NY, USA.

Contributors: All authors had full access to all the data and can take responsibility for the data and analyses. BMW and CT contributed to the review of the data for the conception of the manuscript from an ophthalmology perspective, critical writing, review, shepherding and assessment of the manuscript, and final approval and sign off of the manuscript. L-JH prepared summary tables, provided statistical review, and assisted in the drafting and approved the final version of the manuscript. GB contributed to the design and conduct of the study, participated in the interpretation of the data, and critically reviewed and approved the manuscript. AML contributed to the design and conduct of the study, participated in the interpretation of the data, and critically reviewed and approved the manuscript. CG and L-JH are the guarantors.

Funding: This study was funded by Pfizer UK, Sandwich, UK. The study sponsor participated in the design, analysis, and interpretation of the data, in the writing of the article, and in the decision to submit it for publication.

Competing interests: All authors have completed the ICMJE unified disclosure form at www.icmje.org/coi_disclosure.pdf and declare that BMW, previously an employee of Pfizer Inc, had support from Pfizer Inc for the submitted work; CT, L-JH, and GB, currently employees of Pfizer Inc, had support from Pfizer Inc for the submitted work; and AML, 


\section{What is already known on this topic}

The phosphodiesterase type 5 inhibitor sildenafil citrate has an established safety profile for intermittent use in the management of erectile dysfunction

It is approved in the United States and Europe as daily oral therapy for the chronic treatment of pulmonary arterial hypertension, a progressive debilitating disease

Relevant literature suggests a low incidence of minor, transient ocular effects mediated by partial inhibition of phosphodiesterase type 6 (PDE6), and a recent study in sheep showed intraocular pressure elevated within one hour post-dose

\section{What this study adds}

This phase III study allowed objective assessment of visual function parameters for most patients through 18 months of treatment and collection of subjective reports of ocular adverse events

A dose related increase in transient ocular adverse events mediated by PDE6, such as chromatopsia, cyanopsia, photophobia, visual brightness, and visual disturbances, was seen

Chronic oral dosing of sildenafil for treating patients with pulmonary arterial hypertension did not have a detrimental effect on any aspect of visual function or ocular safety evaluated

as a consultant for Pfizer Inc in the study conduct and in data analysis and interpretation, had support from Pfizer Inc for the submitted work. Ethical approval: Local institutional review boards or independent ethics committees approved the study protocol. All participants gave written informed consent.

Data sharing: No additional data are available.

1 Laties AM. Vision disorders and phosphodiesterase type 5 inhibitors: a review of the evidence to date. Drug Saf 2009;32:1-18.

2 Murad F. Shattuck lecture: nitric oxide and cyclic GMP in cell signaling and drug development. N Engl J Med 2006;355:2003-11.

3 Coggins MP, Bloch KD. Nitric oxide in the pulmonary vasculature. Arterioscler Thromb Vasc Biol 2007;27:1877-85.

4 Kerr NM, Danesh-Meyer HV. Phosphodiesterase inhibitors and the eye. Clin Exp Ophthalmol 2009:37:514-23.

5 Wharton J, Strange JW, Møller GM, Growcott EJ, Ren X, Franklyn AP, et al. Antiproliferative effects of phosphodiesterase type 5 inhibition in human pulmonary artery cells. Am J Respir Crit Care Med 2005;172:105-13.

6 Archer SL, Michelakis ED. Phosphodiesterase type 5 inhibitors for pulmonary arterial hypertension. N Engl J Med 2009;361:1864-71.

7 Sawada N, Itoh H, Miyashita H, Tsujimoto H, Sone M, Yamahara K, et al. Cyclic GMP kinase and RhoA Ser188 phosphorylation integrate pro- and antifibrotic signals in blood vessels. Mol Cell Biol 2009;29:6018-32.

8 McLaughlin VV, Archer SL, Badesch DB, Barst RJ, Farber HW, Lindner JR, et al. ACCF/AHA 2009 expert consensus document on pulmonary hypertension: a report of the American College of Cardiology Foundation Task Force on Expert Consensus Documents and the American Heart Association developed in collaboration with the American College of Chest Physicians; American Thoracic Society Inc; and the Pulmonary Hypertension Association. J Am Coll Cardiol 2009;53:1573-619.

9 Giaid A, Saleh D. Reduced expression of endothelial nitric oxide synthase in the lungs of patients with pulmonary hypertension. N Engl J Med 1995;333:214-21

10 Murray F, MacLean MR, Pyne NJ. Increased expression of the cGMP-inhibited cAMP-specific (PDE3) and cGMP binding cGMP-specific (PDE5) phosphodiesterases in models of pulmonary hypertension. Br J Pharmacol 2002;137:1187-94.

11 Sebkhi A, Strange JW, Phillips SC, Wharton J, Wilkins MR. Phosphodiesterase type 5 as a target for the treatment of hypoxia-induced pulmonary hypertension. Circulation 2003;107:3230-5.

12 Nagendran J, Archer SL, Soliman D, Gurtu V, Moudgil R, Haromy A, et al. Phosphodiesterase type 5 is highly expressed in the hypertrophied human right ventricle, and acute inhibition of phosphodiesterase type 5 improves contractility. Circulation 2007;116:238-48.

13 Foresta C, Caretta N, Zuccarello D, Poletti A, Biagioli A, Caretti L, et al. Expression of the PDE5 enzyme on human retinal tissue: new aspects of PDE5 inhibitors ocular side effects. Eye (Lond) 2008;22:144-9.

14 Pfizer. Viagra (prescribing information). 2011. www.pfizer.com/files/products/uspi_viagra. pdf.

15 Laties A, Ellis P, Koppiker N, Patat A, Stuckey B. Visual function testing in patients and healthy volunteers receiving Viagra [abstract]. Ophthalmic Res 1998;30(suppl 1):177.

16 Laties A, Ellis P, Mollon JD. The effects of sildenafil citrate (Viagra) on color discrimination in volunteers and patients with erectile dysfunction [abstract]. Invest Ophthalmol Vis Sci 1999;40(suppl):S693

17 Gabrieli CB, Regine F, Vingolo EM, Rispoli E, Fabbri A, Isidori A. Subjective visual halos after sildenafil (Viagra) administration: electroretinographic evaluation. Ophthalmology 2001;108:877-81

18 Jägle H, Jägle C, Sérey L, Yu A, Rilk A, Sadowski B, et al. Visual short-term effects of Viagra: double-blind study in healthy young subjects. Am J Ophthalmol 2004;137:842-9.

19 Laties A, Sharlip I. Ocular safety in patients using sildenafil citrate therapy for erectile dysfunction. J Sex Med 2006;3:12-27.

20 Gerometta R, Alvarez LJ, Candia OA. Effects of sildenafil and tadalafil on intraocular pressure in sheep: implications on aqueous humor dynamics. Invest Ophthalmol Vis SCi 2010;51:3139-44

21 Yajima T, Yajima Y, Koppiker N, Grunwald JE, Laties AM. No clinically important effects on intraocular pressure after short-term administration of sildenafil citrate (Viagra). Am J Ophthalmol 2000;129:675-6.

22 Harris A, Kagemann L, Ehrlich R, Ehrlich Y, López CR, Purvin VA. The effect of sildenafil on ocular blood flow. Br J Ophthalmol 2008;92:469-73.

23 Cordell WH, Maturi RK, Costigan TM, Marmor MF, Weleber RG, Coupland SG, for the ERG Testing During Chronic PDE5 Inhibitor Administration (ERG-PDE5i) Consortium.
Retinal effects of 6 months of daily use of tadalafil or sildenafil. Arch Ophthalmol 2009;127:367-73.

24 Grunwald JE, Siu KK, Jacob SS, Dupont J. Effect of sildenafil citrate (Viagra) on the ocular circulation. Am J Ophthalmol 2001;131:751-5.

25 Grunwald JE, Metelitsina T, Grunwald L. Effect of sildenafil citrate (Viagra) on retinal blood vessel diameter. Am J Ophthalmol 2002;133:809-12.

26 McCulley TJ, Luu JK, Marmor MF, Feuer WJ. Effects of sildenafil citrate (Viagra) on choroidal congestion. Ophthalmologica 2002;216:455-8.

27 Metelitsina TI, Grunwald JE, DuPont JC, Ying GS. Effect of Viagra on the foveolar choroidal circulation of AMD patients. Exp Eye Res 2005;81:159-64.

28 Paris G, Sponsel WE, Sandoval SS, Elliott WR, Trigo Y, Sanford DK, et al. Sildenafil increases ocular perfusion. Int Ophthalmol 2001;23:355-8.

29 Dundar SO, Dundar M, Kocak I, Dayanir Y, Ozkan SB. Effect of sildenafil on ocula haemodynamics. Eye 2001;15:507-10.

30 Koksal M, Ozdemir H, Kargi S, Yesilli C, Tomaç S, Mahmutyazicioglu K, et al. The effects of sildenafil on ocular blood flow. Acta Ophthalmol Scand 2005;83:355-9.

31 Pache M, Meyer P, Prünte C, Orgül S, Nuttli I, Flammer J. Sildenafil induces retinal vasodilatation in healthy subjects. Br J Ophthalmol 2002;86:156-8.

32 Polak K, Wimpissinger B, Berisha F, Georgopoulos M, Schmetterer L. Effects of sildenafil on retinal blood flow and flicker-induced retinal vasodilation in healthy subjects. Invest Ophthalmol Vis Sci 2003;44:4872-6.

33 Metelitsina TI, Grunwald JE, DuPont JC, Ying GS, Liu C. Effect of Viagra on retinal vein diameter in AMD patients. Exp Eye Res 2006:83:128-32.

34 Fraunfelder FW, Fraunfelder FT. Central serous chorioretinopathy associated with sildenafil. Retina 2008;28:606-9.

35 Tripathi A, O'Donnell NP. Branch retinal artery occlusion; another complication of sildenafil. Br J Ophthalmol 2000;84:934-5.

36 Bertolucci A, Latkany RA, Gentile RC, Rosen RB. Hemi-retinal artery occlusion associated with sexual activity and sildenafil citrate (Viagra). Acta Ophthalmol Scand 2003:81:198-200.

37 Donahue SP, Taylor RJ. Pupil-sparing third nerve palsy associated with sildenafil citrate (Viagra). Am J Ophthalmol 1998;126:476-7.

38 Acaroglu G, Akinci A, Zilelioglu O. Sildenafil associated pupil-sparing third nerve palsy. $J$ Neuroophthalmol 2006;30:117-9.

39 Galiè N, Ghofrani HA, Torbicki A, Barst RJ, Rubin LJ, Badesch D, for the Sildenafil Use in Pulmonary Arterial Hypertension (SUPER) Study Group. Sildenafil citrate therapy for pulmonary arterial hypertension [published correction in: N Engl J Med 2006;354:2400-1]. N Engl J Med 2005;353:2148-57.

40 Holland GN, Kappel PJ, Van Natta ML, Palella FJ, Lyon AT, Shah KH, for the Studies of the Ocular Complications of AIDS Research Group. Association between abnormal contrast sensitivity and mortality among people with acquired immunodeficiency syndrome. Am J Ophthalmol 2010:149:807-16

41 Harris A, Arend O, Danis RP, Evans D, Wolf S, Martin BJ. Hyperoxia improves contrast sensitivity in early diabetic retinopathy. Br J Ophthalmol 1996;80:209-13.

42 Van Camp G, Renard M, Verougstraete C, Bernard R. Ophthalmologic complications in primary pulmonary hypertension. Chest 1990;98:1543-4.

43 Akduman L, Del Priore LV, Kaplan HJ, Meredith T. Uveal effusion syndrome associated with primary pulmonary hypertension and vomiting. Am J Ophthalmol 1996;121:578-80.

44 Arevalo JF, Lowder CY, Muci-Mendoza R. Ocular manifestations of systemic lupus erythematosus. Curr Opin Ophthalmol 2002;13:404-10.

45 Read RW. Clinical mini-review: systemic lupus erythematosus and the eye. Ocul Immuno Inflamm 2004;12:87-99.

46 Wong TY, Duncan BB, Golden SH, Klein BE, Couper DJ, Hubbard LD, et al. Associations between the metabolic syndrome and retinal microvascular signs: the Atherosclerosis Risk in Communities study. Invest Ophthalmol Vis Sci 2004:45:2949-54.

47 Scheider A, Asiyo M, Habersetzer K. Serous retinal detachment in $\mathrm{O} 2$ therapy of primary pulmonary hypertension. Fortschr Ophthalmol 1991;88:346-9.

48 Hammond CJ, Chauhan DS, Stanford MS. Pulmonary hypertension and diffuse macular edema responsive to acetazolamide. Arch Ophthalmol 1998;116:1535-6.

49 Saran BR, Brucker AJ, Bandello F, Verougstraete C. Familial primary pulmonary hypertension and associated ocular findings. Retina 2001;21:34-9.

$50 \mathrm{Krohn} \mathrm{J}$, Bjune $\mathrm{C}$. Uveal effusion and angle-closure glaucoma in primary pulmonary hypertension. Am J Ophthalmol 2003;135:705-6.

51 Zoumalan $\mathrm{Cl}$, Zamanian RT, Doyle RL, Marmor MF. ERG evaluation of daily, high-dose sildenafil usage. Doc Ophthalmol 2009;118:225-31.

52 Pomeranz HD, Smith KH, Hart WM Jr, Egan RA. Sildenafil-associated nonarteritic anterior ischemic optic neuropathy. Ophthalmology 2002;109:584-7.

53 Hattenhauer MG, Leavitt JA, Hodge DO, Grill R, Gray DT. Incidence of nonarteritic anterior ischemic optic neuropathy. Am J Ophthalmol 1997;123:103-7.

54 Johnson LN, Arnold AC. Incidence of nonarteritic and arteritic anterior ischemic optic neuropathy: population based study in the state of Missouri and Los Angeles County, California. J Neuroophthalmol 1994;14:38-44. 
$55 \mathrm{Xu} \mathrm{L}$, Wang $\mathrm{Y}$, Jonas JB. Incidence of nonarteritic anterior ischemic optic neuropathy in adult Chinese: the Beijing Eye Study. Eur J Ophthalmol 2007;17:459-60.

56 Gorkin L, Hvidsten K, Sobel RE, Siegel R. Sildenafil citrate use and the incidence of nonarteritic anterior ischemic optic neuropathy. Int J Clin Pract 2006;60:500-3.

57 Hayreh SS. Non-arteritic anterior ischaemic optic neuropathy and phosphodiesterase- 5 inhibitors. Br J Ophthalmol 2008;92:1577-80.

58 Wallis R, Leishman DJ, Pullman L, Graepel P, Heywood R. Effects of sildenafil on electroretinograms in dogs and retinal histopathology in rats and dogs. Ophthalmic Res 1998;30(suppl 1):68.

59 Luu JK, Chappelow AV, McCulley TJ, Marmor MF. Acute effects of sildenafil on the electroretinogram and multifocal electroretinogram. Am J Ophthalmol 2001;132:388-94.

60 Laties AM, Zrenner E. Viagra (sildenafil citrate) and ophthalmology. Prog Retin Eye Res 2002;21:485-506.

61 Becker RC, Kirchner-Pauli E. Assessment of retinal function during treatment with sildenafil. Invest Ophthalmol Vis Sci 2005;46:E-Abstract 3920.
62 Laties A, Sharlip I. Ocular safety in patients using sildenafil citrate therapy for erectile dysfunction. J Sex Med 2006;3:12-27.

Accepted: 14 November 2011

Cite this as: BMJ 2012;344:e554

This is an open-access article distributed under the terms of the Creative Commons Attribution Non-commercial License, which permits use, distribution, and reproduction in any medium, provided the original work is properly cited, the use is non commercial and is otherwise in compliance with the license. See: http://creativecommons.org/licenses/bync/2.0/ and http://creativecommons.org/licenses/by-nc/2.0/legalcode. 


\section{Tables}

\begin{tabular}{|c|c|c|c|c|}
\hline \multirow[b]{2}{*}{ Characteristic } & \multirow[b]{2}{*}{ Placebo $(n=70)$} & \multicolumn{3}{|c|}{ Sildenafil } \\
\hline & & $20 \mathrm{mg}(\mathrm{n}=69)$ & $40 \mathrm{mg}(\mathrm{n}=67)$ & $80 \mathrm{mg}(\mathrm{n}=71)$ \\
\hline Female sex & $57(81)$ & $49(71)$ & $47(70)$ & $56(79)$ \\
\hline Mean (SD) age (years) & $49(17)$ & $47(14)$ & $51(15)$ & $48(15)$ \\
\hline \multicolumn{5}{|l|}{ Racial/ethnic background: } \\
\hline White & $61(87)$ & $59(86)$ & $58(87)$ & $58(82)$ \\
\hline Black & $1(1)$ & 0 & $4(6)$ & $1(1)$ \\
\hline Asian & $2(3)$ & $6(9)$ & $2(3)$ & $9(13)$ \\
\hline Other & $6(9)$ & $4(6)$ & $3(5)$ & $3(4)$ \\
\hline Mean (SD) weight $(\mathrm{kg})$ & $74(19)$ & $71(17)$ & $75(17)$ & $71(17)$ \\
\hline \multicolumn{5}{|l|}{ WHO functional class: } \\
\hline 1 & $1(1)$ & 0 & 0 & 0 \\
\hline II & $32(46)$ & $24(35)$ & $23(34)$ & $28(39)$ \\
\hline III & $34(49)$ & $40(58)$ & $44(66)$ & $42(59)$ \\
\hline IV & $3(4)$ & $5(7)$ & 0 & $1(1)$ \\
\hline \multicolumn{5}{|l|}{ Cause of pulmonary arterial hypertension: } \\
\hline Idiopathic & $42(60)$ & $44(64)$ & $43(64)$ & $46(65)$ \\
\hline Connective tissue disease & $22(31)$ & $21(30)$ & $20(30)$ & $21(30)$ \\
\hline $\begin{array}{l}\text { Repaired congenital systemic to pulmonary } \\
\text { shunts }\end{array}$ & $6(9)$ & $4(6)$ & $4(6)$ & $4(6)$ \\
\hline History of glaucoma or ocular hypertension & 0 & $1(1)$ & $5(8)$ & 0 \\
\hline $\begin{array}{l}\text { Mean }(95 \% \mathrm{Cl}) \text { intraocular pressure, right eye }(\mathrm{mm} \\
\mathrm{Hg})\end{array}$ & $15.2(14.0$ to 16.4$)$ & $14.8(14.0$ to 15.6$)$ & $14.9(14.2$ to 15.6$)$ & $14.4(13.7$ to 15.1$)$ \\
\hline Normal visual field, right eye ${ }^{\star}$ & $52 / 68(77)$ & $48 / 67(72)$ & $43 / 66(65)$ & $47 / 66(71)$ \\
\hline Mean (SD) contrast sensitivity, right eye & $1.58(0.20)(n=62)$ & $1.63(0.17)(n=58)$ & $1.61(0.16)(n=61)$ & $1.60(0.19)(n=63)$ \\
\hline \multicolumn{5}{|l|}{ Visual acuity (Snellen), right eye: } \\
\hline $20 / 20$ & $44(63)$ & $51(74)$ & $48(72)$ & $51(72)$ \\
\hline $20 / 30$ & $15(21)$ & $12(17)$ & $13(19)$ & $11(16)$ \\
\hline $20 / 40$ & $4(6)$ & $1(1)$ & $1(2)$ & $3(4)$ \\
\hline $20 / 60$ & 0 & $1(1)$ & 0 & $2(3)$ \\
\hline $20 / 120$ & $1(1)$ & 0 & 0 & 0 \\
\hline Missing & $6(9)$ & $4(6)$ & $5(8)$ & $4(6)$ \\
\hline
\end{tabular}

*Data missing for two participants in placebo and sildenafil $20 \mathrm{mg}$ groups, one in sildenafil $40 \mathrm{mg}$ group, and five in sildenafil $80 \mathrm{mg}$ group. 
Table 2| Baseline incidence of characteristic ocular abnormalities seen in right heart failure by cause and warfarin treatment, right eye. Values are numbers (percentages)

\begin{tabular}{|c|c|c|c|c|c|}
\hline \multirow[b]{2}{*}{ Abnormality } & \multirow[b]{2}{*}{$\begin{array}{l}\text { All participants* } \\
\qquad(n=260)\end{array}$} & \multicolumn{2}{|c|}{ Cause of pulmonary arterial hypertension $†$} & \multicolumn{2}{|c|}{ Warfarin treatment } \\
\hline & & Primary $(n=164)$ & $\begin{array}{l}\text { Associated with connective tissue } \\
\text { disease }(n=81)\end{array}$ & Yes $(n=114)$ & No $(n=146)$ \\
\hline Dilated episcleral blood vessels & $44(17)$ & $29(18)$ & $12(15)$ & $21(18)$ & $23(16)$ \\
\hline Conjunctival injection & $34(13)$ & $22(13)$ & $7(9)$ & $17(15)$ & $17(12)$ \\
\hline Abnormal blood vessels & $32(12)$ & $23(14)$ & $8(10)$ & $12(11)$ & $20(14)$ \\
\hline Retinal vein engorgement & $10(4)$ & $7(4)$ & $3(4)$ & $2(2)$ & $8(6)$ \\
\hline Conjunctival oedema & $3(1)$ & $2(1)$ & $1(1)$ & $2(2)$ & $1(1)$ \\
\hline
\end{tabular}

*Includes all participants with visual assessment data.

†Data missing for 15 participants. 
Table 3/ Changes from baseline to week 12 in contrast sensitivity and best corrected visual acuity (spherical equivalent) in right eye during 12 week, double masked study*

\begin{tabular}{|c|c|c|c|c|}
\hline \multirow[b]{2}{*}{ Measure of visual function } & \multirow[b]{2}{*}{ Placebo $(n=68)$} & \multicolumn{3}{|c|}{ Sildenafil } \\
\hline & & $20 \mathrm{mg}(\mathrm{n}=67)$ & $40 \mathrm{mg}(\mathrm{n}=66)$ & $80 \mathrm{mg}(\mathrm{n}=65)$ \\
\hline \multicolumn{5}{|l|}{ Contrast sensitivity†: } \\
\hline Improvement & $2(3)$ & $3(5)$ & $8(12)$ & $5(8)$ \\
\hline No change & $44(65)$ & $44(66)$ & $40(61)$ & $41(63)$ \\
\hline Deterioration & $9(13)$ & $5(8)$ & $5(8)$ & $9(14)$ \\
\hline Missing & $13(19)$ & $15(22)$ & $13(20)$ & $10(15)$ \\
\hline \multicolumn{5}{|l|}{ Visual acuitył: } \\
\hline Improvement & $7(10)$ & $5(8)$ & $1(2)$ & $2(3)$ \\
\hline No change & $46(68)$ & $50(75)$ & $53(80)$ & $53(82)$ \\
\hline Deterioration & $7(10)$ & $2(3)$ & $3(5)$ & $5(8)$ \\
\hline Missing & $8(12)$ & $10(15)$ & $9(14)$ & $5(8)$ \\
\hline
\end{tabular}

*Data are numbers (percentages) and include all participants with week 12 visit.

†Improvement=increase of $\geq 0.15$ in log contrast sensitivity; no change=change of $<0.15$ in log contrast sensitivity; deterioration=decrease of $\geq 0.15$ in log contrast sensitivity; and missing=not possible to calculate owing to missing data; $P=0.039$ for comparison in contrast sensitivity improvement between sildenafil 40 mg and placebo groups.

†Improvement=increase of $\geq 1$ line read versus baseline (baseline assessment 6/60, 6/36, 6/24, 6/18,6/12, or 6/9); no change=no change in number of lines read compared with baseline or change within last three lines of chart $(6 / 6,6 / 5$, or $6 / 4)$; deterioration=decrease of $\geq 1$ line compared with baseline (baseline assessment $6 / 60,6 / 36,6 / 24,6 / 18,6 / 12,6 / 9$, or $6 / 6)$; and missing=not possible to calculate owing to missing data. 
Table 4 | Overall frequency of visual field changes in right eye during 12 week, double masked study*

\begin{tabular}{lcccc} 
& & \multicolumn{3}{c}{ Result at baseline } \\
\cline { 2 - 5 } Treatment & Result at week 12 & Normal & Abnormal & Missingt \\
Placebo ( $\mathrm{n}=68)$ & Normal & $39(57)$ & $4(6)$ & $4(6)$ \\
\cline { 2 - 5 } & Abnormal & $7(10)$ & $2(3)$ & $1(2)$ \\
\cline { 2 - 5 } & Missing & $6(9)$ & 0 & $5(7)$ \\
\hline Sildenafil $20 \mathrm{mg}(\mathrm{n}=67)$ & Normal & $43(64)$ & $5(8)$ & $2(3)$ \\
\cline { 2 - 5 } & Abnormal & $2(3)$ & $4(6)$ & 0 \\
\cline { 2 - 5 } & Missing† & $3(5)$ & $3(5)$ & $5(8)$ \\
\hline Sildenafil $40 \mathrm{mg}(\mathrm{n}=66)$ & Normal & $34(52)$ & $7(11)$ & $6(9)$ \\
\cline { 2 - 5 } & Abnormal & $1(2)$ & $3(5)$ & $1(2)$ \\
\cline { 2 - 5 } & Missingt & $8(12)$ & $4(6)$ & $2(3)$ \\
\hline Sildenafil $80 \mathrm{mg}(\mathrm{n}=66)$ & Normal & $38(58)$ & $3(5)$ & $2(3)$ \\
\cline { 2 - 5 } & Abnormal & $3(5)$ & $8(12)$ & $2(3)$ \\
\cline { 2 - 5 } & Missing $\dagger$ & $6(9)$ & $1(2)$ & $3(5)$ \\
\hline
\end{tabular}

*Data are numbers (percentages) and include all participants with week 12 visit. †Not possible to calculate owing to missing assessment. 
Table 5 | Incidence of all causality eye disorder adverse events reported during 12 week, double masked study, either eye. Values are numbers (percentages, $95 \% \mathrm{Cl}$ )

\begin{tabular}{|c|c|c|c|c|}
\hline \multirow[b]{2}{*}{ Adverse event (MedDRA preferred term) } & \multirow[b]{2}{*}{ Placebo $(n=70)$} & \multicolumn{3}{|c|}{ Sildenafil } \\
\hline & & $20 \mathrm{mg}(\mathrm{n}=69)$ & $40 \mathrm{mg}(\mathrm{n}=67)$ & $80 \mathrm{mg}(\mathrm{n}=71)$ \\
\hline Abnormal sensation in eye & 0 & $2(2.9,0.35$ to 10.08$)$ & $1(1.5,0.04$ to 8.04$)$ & 0 \\
\hline Accommodation disorder & $1(1.4,0.04$ to 7.70$)$ & 0 & 0 & 0 \\
\hline Blepharitis & $1(1.4,0.04$ to 7.70$)$ & $1(1.4,0.04$ to 7.81$)$ & 0 & 0 \\
\hline Cataract bilateral NOS & $1(1.4,0.04$ to 7.70$)$ & 0 & $1(1.5,0.04$ to 8.04$)$ & 0 \\
\hline Cataract unilateral & 0 & 0 & $1(1.5,0.04$ to 8.04$)$ & 0 \\
\hline Chromatopsia & $1(1.4,0.04$ to 7.70$)$ & $1(1.4,0.04$ to 7.81$)$ & $1(1.5,0.04$ to 8.04$)$ & $3(4.2,0.88$ to 11.86$)$ \\
\hline Conjunctival haemorrhage & 0 & 0 & 0 & $1(1.4,0.04$ to 7.60$)$ \\
\hline Conjunctival hyperaemia & 0 & $1(1.4,0.04$ to 7.81$)$ & $1(1.5,0.04$ to 8.04$)$ & 0 \\
\hline Conjunctivitis & $1(1.4,0.04$ to 7.70$)$ & 0 & $1(1.5,0.04$ to 8.04$)$ & $1(1.4,0.04$ to 7.60$)$ \\
\hline Cyanopsia & 0 & 0 & $1(1.5,0.04$ to 8.04$)$ & $3(4.2,0.88$ to 11.86$)$ \\
\hline Diplopia & 0 & $1(1.4,0.04$ to 7.81$)$ & $1(1.5,0.04$ to 8.04$)$ & $1(1.4,0.04$ to 7.60$)$ \\
\hline Dry eye NOS & 0 & $1(1.4,0.04$ to 7.81$)$ & 0 & 0 \\
\hline$\underline{\text { Episcleral hyperaemia }}$ & $2(2.9,0.35$ to 9.94$)$ & 0 & 0 & 0 \\
\hline Eye haemorrhage NOS & $1(1.4,0.04$ to 7.70$)$ & $1(1.4,0.04$ to 7.81$)$ & $1(1.5,0.04$ to 8.04$)$ & $1(1.4,0.04$ to 7.60$)$ \\
\hline Eye inflammation NOS & $1(1.4,0.04$ to 7.70$)$ & 0 & 0 & 0 \\
\hline Eye irritation & 0 & $2(2.9,0.35$ to 10.08$)$ & 0 & $2(2.8,0.34$ to 9.81$)$ \\
\hline Eye oedema & $1(1.4,0.04$ to 7.70$)$ & 0 & 0 & 0 \\
\hline Eye pain & $1(1.4,0.04$ to 7.70$)$ & $1(1.4,0.04$ to 7.81$)$ & 0 & $3(4.2,0.88$ to 11.86$)$ \\
\hline Eye pruritus & $1(1.4,0.04$ to 7.70$)$ & 0 & $1(1.5,0.04$ to 8.04$)$ & 0 \\
\hline Eye redness & $1(1.4,0.04$ to 7.70$)$ & 0 & $1(1.5,0.04$ to 8.04$)$ & 0 \\
\hline Eyelid oedema & $1(1.4,0.04$ to 7.70$)$ & $1(1.4,0.04$ to 7.81$)$ & 0 & 0 \\
\hline Halo vision & $1(1.4,0.04$ to 7.70$)$ & 0 & 0 & $2(2.8,0.34$ to 9.81$)$ \\
\hline Lacrimation increased & 0 & 0 & $1(1.5,0.04$ to 8.04$)$ & 0 \\
\hline Lenticular opacities & $1(1.4,0.04$ to 7.70$)$ & 0 & $1(1.5,0.04$ to 8.04$)$ & 0 \\
\hline Macular oedema & 0 & $1(1.4,0.04$ to 7.81$)$ & 0 & 0 \\
\hline Ocular discomfort & 0 & 0 & $1(1.5,0.04$ to 8.04$)$ & 0 \\
\hline Ocular hyperaemia & 0 & $1(1.4,0.04$ to 7.81$)$ & 0 & 0 \\
\hline Ocular vascular disorder & 0 & 0 & 0 & $1(1.4,0.04$ to 7.60$)$ \\
\hline Photophobia & 0 & 0 & 0 & $4(5.6,1.56$ to 13.80$)$ \\
\hline Photophobia aggravated & 0 & 0 & 0 & $1(1.4,0.04$ to 7.60$)$ \\
\hline Retinal disorder & 0 & 0 & $1(1.4,0.04$ to 8.04$)$ & 0 \\
\hline Retinal haemorrhage & 0 & $1(1.4,0.04$ to 7.81$)$ & $2(3.0,0.36$ to 10.37$)$ & $1(1.4,0.04$ to 7.60$)$ \\
\hline Retinal pigment epitheliopathy & 0 & 0 & 0 & $1(1.4,0.04$ to 7.60$)$ \\
\hline Vision blurred & $4(5.7,1.58$ to 13.99$)$ & $3(4.3,0.91$ to 12.18$)$ & $2(3.0,0.36$ to 10.37$)$ & $4(5.6,1.56$ to 13.80$)$ \\
\hline Visual acuity reduced & 0 & 0 & $2(3.0,0.36$ to 10.37$)$ & $1(1.4,0.04$ to 7.60$)$ \\
\hline Visual brightness & 0 & 0 & 0 & $2(2.8,0.34$ to 9.81$)$ \\
\hline Visual disturbance NOS & 0 & 0 & $3(4.5,0.93$ to 12.53$)$ & $5(7.0,2.33$ to 15.67$)$ \\
\hline Xanthopsia & 0 & 0 & 0 & $1(1.4,0.04$ to 7.60$)$ \\
\hline
\end{tabular}

MedDRA=Medical Dictionary for Regulatory Activities; NOS=not otherwise specified. 
Table 6 | Overall frequency of ocular findings based on slit lamp and funduscopy examinations in right eye at baseline and week 12 during 12 week, double masked study*

\begin{tabular}{|c|c|c|c|c|}
\hline \multirow[b]{2}{*}{ Treatment } & \multirow[b]{2}{*}{ Result at week 12} & \multicolumn{3}{|c|}{ Result at baseline } \\
\hline & & Normal & Abnormal & Missing $†$ \\
\hline \multicolumn{5}{|c|}{ Serous retinal detachment } \\
\hline \multirow{3}{*}{ Placebo $(n=70)$} & Normal & $60(86)$ & - & $4(6)$ \\
\hline & Abnormal & - & - & - \\
\hline & Missing† & $5(7)$ & - & \\
\hline \multirow[t]{3}{*}{ Sildenafil 20 mg (n=69) } & Normal & $57(83)$ & - & $8(12)$ \\
\hline & Abnormal & - & - & - \\
\hline & Missing & $4(6)$ & - & - \\
\hline \multirow[t]{3}{*}{ Sildenafil 40 mg (n=67) } & Normal & $56(84) \ddagger$ & - & $6(9)$ \\
\hline & Abnormal & - & - & - \\
\hline & Missing† & $4(6)$ & - & - \\
\hline \multirow[t]{3}{*}{ Sildenafil 80 mg $(n=71)$} & Normal & $61(86)$ & - & $7(10)$ \\
\hline & Abnormal & - & - & - \\
\hline & Missing† & $2(3)$ & - & - \\
\hline \multicolumn{5}{|l|}{ Choroidal detachment } \\
\hline \multirow{3}{*}{ Placebo $(n=70)$} & Normal & $60(86)$ & - & $4(6)$ \\
\hline & Abnormal & - & - & - \\
\hline & Missing† & $5(7)$ & - & - \\
\hline \multirow[t]{3}{*}{ Sildenafil 20 mg (n=69) } & Normal & $57(83)$ & - & $8(12)$ \\
\hline & Abnormal & - & - & - \\
\hline & Missing† & $4(6)$ & - & - \\
\hline \multirow[t]{3}{*}{ Sildenafil 40 mg (n=67) } & Normal & $56(84) \ddagger$ & - & $6(9)$ \\
\hline & Abnormal & - & - & - \\
\hline & Missing $†$ & $4(6)$ & - & - \\
\hline \multirow[t]{3}{*}{ Sildenafil 80 mg $(n=71)$} & Normal & $61(86)$ & - & $7(10)$ \\
\hline & Abnormal & - & - & - \\
\hline & Missing $†$ & $2(3)$ & - & - \\
\hline \multicolumn{5}{|l|}{ Conjunctival injection } \\
\hline \multirow{3}{*}{ Placebo $(n=70)$} & Normal & $47(67)$ & $4(6)$ & $3(4)$ \\
\hline & Abnormal & - & $8(11)$ & $2(3)$ \\
\hline & Missing† & $5(7)$ & - & - \\
\hline \multirow[t]{3}{*}{ Sildenafil 20 mg (n=69) } & Normal & $49(71)$ & $4(6)$ & $7(10)$ \\
\hline & Abnormal & $2(3)$ & $2(3)$ & $1(1)$ \\
\hline & Missing† & $3(4)$ & $1(1)$ & - \\
\hline \multirow[t]{3}{*}{ Sildenafil 40 mg ( $n=67)$} & Normal & $43(64)$ & $6(9)$ & $6(9)$ \\
\hline & Abnormal & $2(3)$ & $6(9)$ & - \\
\hline & Missing† & $4(6)$ & - & - \\
\hline \multirow[t]{3}{*}{ Sildenafil 80 mg $(n=71)$} & Normal & $47(66)$ & $3(4)$ & $7(10)$ \\
\hline & Abnormal & $2(3)$ & $9(13)$ & - \\
\hline & Missing† & $1(1)$ & $1(1)$ & - \\
\hline \multicolumn{5}{|l|}{ Conjunctival oedema } \\
\hline \multirow[t]{3}{*}{ Placebo $(n=70)$} & Normal & $56(80)$ & $1(1)$ & $5(7)$ \\
\hline & Abnormal & $1(1)$ & $1(1)$ & - \\
\hline & Missingt & $5(7)$ & - & - \\
\hline \multirow[t]{3}{*}{ Sildenafil 20 mg ( $n=69)$} & Normal & $55(80)$ & $1(1)$ & $8(12)$ \\
\hline & Abnormal & - & $1(1)$ & - \\
\hline & Missing† & $4(6)$ & - & - \\
\hline Sildenafil 40 mg ( $n=67)$ & Normal & $56(84)$ & $1(2)$ & $6(9)$ \\
\hline
\end{tabular}


Table 6 (continued)

\begin{tabular}{|c|c|c|c|c|}
\hline \multirow[b]{2}{*}{ Treatment } & \multirow[b]{2}{*}{ Result at week 12} & \multicolumn{3}{|c|}{ Result at baseline } \\
\hline & & Normal & Abnormal & Missing $†$ \\
\hline & Abnormal & - & - & - \\
\hline & Missing† & $4(6)$ & - & - \\
\hline \multirow[t]{3}{*}{ Sildenafil $80 \mathrm{mg}(\mathrm{n}=71)$} & Normal & $60(85)$ & $1(1)$ & $7(10)$ \\
\hline & Abnormal & - & - & - \\
\hline & Missingt & $2(3)$ & - & - \\
\hline \multicolumn{5}{|c|}{ Dilated episcleral blood vessels } \\
\hline \multirow[t]{3}{*}{ Placebo $(n=70)$} & Normal & $45(64)$ & $4(6)$ & $3(4)$ \\
\hline & Abnormal & $2(3)$ & $8(11)$ & $2(3)$ \\
\hline & Missingt & $4(6)$ & $1(1)$ & - \\
\hline \multirow[t]{3}{*}{ Sildenafil 20 mg ( $n=69)$} & Normal & $44(64)$ & $5(7)$ & $5(7)$ \\
\hline & Abnormal & $2(3)$ & $6(9)$ & $3(4)$ \\
\hline & Missingt & $3(4)$ & $1(1)$ & - \\
\hline \multirow[t]{3}{*}{ Sildenafil 40 mg ( $n=67)$} & Normal & $46(69)$ & $5(8)$ & $5(8)$ \\
\hline & Abnormal & $1(2)$ & $5(8)$ & $1(2)$ \\
\hline & Missingt & $3(4)$ & $1(2)$ & - \\
\hline \multirow[t]{3}{*}{ Sildenafil 80 mg ( $n=71)$} & Normal & $43(61)$ & $6(9)$ & $5(7)$ \\
\hline & Abnormal & $4(6)$ & $8(11)$ & $2(3)$ \\
\hline & Missingt & - & $2(3)$ & - \\
\hline \multicolumn{5}{|l|}{ Abnormal blood vessels } \\
\hline \multirow[t]{3}{*}{ Placebo $(n=70)$} & Normal & $48(69)$ & $3(4)$ & $4(6)$ \\
\hline & Abnormal & $3(4)$ & $6(9)$ & - \\
\hline & Missingt & $4(6)$ & $1(1)$ & - \\
\hline \multirow[t]{3}{*}{ Sildenafil 20 mg ( $n=69)$} & Normal & $47(68)$ & $2(3)$ & $7(10)$ \\
\hline & Abnormal & $2(3)$ & $5(7)$ & $1(1)$ \\
\hline & Missingt & $2(4)$ & $1(1)$ & - \\
\hline \multirow[t]{3}{*}{ Sildenafil 40 mg ( $n=67)$} & Normal & $50(75)$ & $1(2)$ & $6(9)$ \\
\hline & Abnormal & - & $6(9)$ & - \\
\hline & Missingt & $4(6)$ & - & - \\
\hline \multirow[t]{3}{*}{ Sildenafil $80 \mathrm{mg}(\mathrm{n}=71)$} & Normal & $51(72)$ & $3(4)$ & $5(7)$ \\
\hline & Abnormal & $3(4)$ & $4(6)$ & $2(3)$ \\
\hline & Missingt & $2(3)$ & - & - \\
\hline \multicolumn{5}{|l|}{ Retinal vein engorgement } \\
\hline \multirow[t]{3}{*}{ Placebo $(n=70)$} & Normal & $55(79)$ & $4(6)$ & $4(6)$ \\
\hline & Abnormal & - & $1(1)$ & - \\
\hline & Missingt & $4(6)$ & $1(1)$ & - \\
\hline \multirow[t]{3}{*}{ Sildenafil 20 mg (n=69) } & Normal & $53(77)$ & - & $8(12)$ \\
\hline & Abnormal & - & $4(6)$ & - \\
\hline & Missingt & $4(6)$ & - & - \\
\hline \multirow[t]{3}{*}{ Sildenafil 40 mg ( $n=67)$} & Normal & $51(76) \ddagger$ & $1(2)$ & $6(9)$ \\
\hline & Abnormal & $1(2)$ & $3(5)$ & - \\
\hline & Missingt & $4(6)$ & - & - \\
\hline \multirow[t]{3}{*}{ Sildenafil 80 mg ( $n=71)$} & Normal & $59(83)$ & $1(1)$ & $7(10)$ \\
\hline & Abnormal & - & $1(1)$ & - \\
\hline & Missing $\dagger$ & $2(3)$ & - & - \\
\hline \multicolumn{5}{|c|}{ No of participants with ocular abnormalities } \\
\hline \multirow[t]{2}{*}{ Placebo $(n=70)$} & Normal & $36(51)$ & $4(6)$ & $1(1)$ \\
\hline & Abnormal & $1(1)$ & $19(27)$ & $3(4)$ \\
\hline
\end{tabular}




\section{Table 6 (continued)}

\begin{tabular}{lcccc} 
& & \multicolumn{3}{c}{ Result at baseline } \\
\cline { 2 - 5 } Treatment & Result at week 12 & Normal & Abnormal & Missing† \\
& Missing† & $3(4)$ & $2(3)$ & $1(1)$ \\
\hline Sildenafil $20 \mathrm{mg}(\mathrm{n}=69)$ & Normal & $34(49)$ & $7(10)$ & $4(6)$ \\
\cline { 2 - 5 } & Abnormal & $4(6)$ & $12(17)$ & $4(6)$ \\
\cline { 2 - 5 } & Missing† & $2(3)$ & $2(3)$ & - \\
\hline Sildenafil $40 \mathrm{mg}(\mathrm{n}=67)$ & Normal & $31(46)$ & $7(10)$ & $5(8)$ \\
\cline { 2 - 5 } & Abnormal & $2(3)$ & $17(25)$ & $1(2)$ \\
\cline { 2 - 5 } & Missing† & $3(5)$ & $1(2)$ & - \\
\hline \multirow{2}{*}{ Sildenafil $80 \mathrm{mg}(\mathrm{n}=71)$} & Normal & $31(44)$ & $8(11)$ & $4(6)$ \\
\cline { 2 - 5 } & Abnormal & $5(7)$ & $17(24)$ & $3(4)$ \\
\cline { 2 - 5 } & Missing & & $2(3)$ & $1(1)$ \\
\hline
\end{tabular}

*Data are numbers (percentages) and include all participants with week 12 visit. †Not possible to calculate change owing to missing assessment.

$\ddagger$ Assessment not done for 1 participant. 
Table 7 | Cross tabulation of double masked study dose groups by dose during open label extension study

\begin{tabular}{|c|c|c|c|c|c|}
\hline \multicolumn{2}{|c|}{ Open label extension study } & \multicolumn{4}{|c|}{ Double masked study } \\
\hline Visit & Sildenafil dose ( $\mathrm{mg}$ tid) & Placebo $(n=67)$ & Sildenafil $20 \mathrm{mg}$ tid $(\mathrm{n}=65)$ & Sildenafil $40 \mathrm{mg}$ tid $(n=63)$ & Sildenafil $80 \mathrm{mg}$ tid $(\mathrm{n}=64)$ \\
\hline \multirow[t]{2}{*}{ Week 12} & 40 & $67(100)$ & $65(100)$ & $63(100)$ & \\
\hline & 80 & & & & $64(100)$ \\
\hline \multirow[t]{3}{*}{ Week 18} & 20 & $2(3)$ & & $1(2)$ & \\
\hline & 40 & $23(34)$ & $16(25)$ & $20(32)$ & $1(2)$ \\
\hline & 80 & $39(58)$ & $49(75)$ & $42(67)$ & $63(98)$ \\
\hline \multirow[t]{3}{*}{ Week 24} & 20 & $2(3)$ & $1(2)$ & $1(2)$ & \\
\hline & 40 & $1(2)$ & $1(2)$ & & $2(3)$ \\
\hline & 80 & $56(84)$ & $62(95)$ & $62(98)$ & $62(97)$ \\
\hline \multirow[t]{3}{*}{ Month 9} & 20 & $2(3)$ & & $1(2)$ & \\
\hline & 40 & $1(2)$ & $1(2)$ & & $2(3)$ \\
\hline & 80 & $54(81)$ & $61(94)$ & $61(97)$ & $61(95)$ \\
\hline \multirow[t]{3}{*}{ Month 12} & 20 & $2(3)$ & & $1(2)$ & \\
\hline & 40 & $1(2)$ & $1(2)$ & & $2(3)$ \\
\hline & 80 & $49(73)$ & $60(92)$ & $56(89)$ & $58(92)$ \\
\hline \multirow[t]{3}{*}{ Month 15} & 20 & $1(2)$ & & & \\
\hline & 40 & $1(2)$ & $1(2)$ & & $2(3)$ \\
\hline & 80 & $36(54)$ & $38(59)$ & $45(71)$ & $41(64)$ \\
\hline \multirow[t]{2}{*}{ Month 18} & 40 & $1(2)$ & & & $1(2)$ \\
\hline & 80 & $17(25)$ & $22(34)$ & $26(41)$ & $21(33)$ \\
\hline \multirow[t]{2}{*}{ Month 21} & 40 & $1(2)$ & & & $1(2)$ \\
\hline & 80 & $4(6)$ & $4(6)$ & $8(13)$ & $4(6)$ \\
\hline \multirow[t]{3}{*}{ Month 33} & 20 & $1(2)$ & & $1(2)$ & \\
\hline & 40 & $1(2)$ & $1(2)$ & & $2(3)$ \\
\hline & 80 & $47(70)$ & $55(85)$ & $56(89)$ & $54(84)$ \\
\hline
\end{tabular}

tid=three times daily 


\begin{tabular}{|c|c|}
\hline Adverse event (MedDRA preferred term) & Sildenafil $(n=259)$ \\
\hline Abnormal sensation in eye & $1(0.4,0.01$ to 2.13$)$ \\
\hline Cataract & $2(0.8,0.09$ to 2.76$)$ \\
\hline Cataract bilateral NOS & $1(0.4,0.01$ to 2.13$)$ \\
\hline Cataract cortical & $1(0.4,0.01$ to 2.13$)$ \\
\hline Cataract nuclear & $1(0.4,0.01$ to 2.13$)$ \\
\hline Cataract unilateral & $2(0.8,0.09$ to 2.76$)$ \\
\hline Choroidal detachment & $1(0.4,0.01$ to 2.13$)$ \\
\hline Chromatopsia & $7(2.7,1.09$ to 5.49$)$ \\
\hline Conjunctival hyperaemia & $12(4.6,2.42$ to 7.95$)$ \\
\hline Conjunctival oedema & $1(0.4,0.01$ to 2.13$)$ \\
\hline Conjunctivitis & $2(0.8,0.09$ to 2.76$)$ \\
\hline Conjunctivitis allergic & $1(0.4,0.01$ to 2.13$)$ \\
\hline Cyanopsia & $4(1.5,0.42$ to 3.91$)$ \\
\hline Diplopia & $2(0.8,0.09$ to 2.76$)$ \\
\hline Dry eye NOS & $2(0.8,0.09$ to 2.76$)$ \\
\hline Episcleral hyperaemia & $10(3.9,1.87$ to 6.99$)$ \\
\hline Episcleritis NOS & $1(0.4,0.01$ to 2.13$)$ \\
\hline Eye disorder NOS & $2(0.8,0.09$ to 2.76$)$ \\
\hline Eye haemorrhage NOS & $6(2.3,(0.85$ to 4.97$)$ \\
\hline Eye inflammation NOS & $1(0.4,0.01$ to 2.13$)$ \\
\hline Eye irritation & $3(1.2,0.24$ to 3.35$)$ \\
\hline Eye pain & $3(1.2,0.24$ to 3.35$)$ \\
\hline Eye pruritus & $1(0.4,0.01$ to 2.13$)$ \\
\hline Eye redness & $3(1.2,0.24$ to 3.35$)$ \\
\hline Eye swelling & $1(0.4,0.01$ to 2.13$)$ \\
\hline Eyelid disorder NOS & $1(0.4,0.01$ to 2.13$)$ \\
\hline Eyelid oedema & $1(0.4,0.01$ to 2.13$)$ \\
\hline Eyelid ptosis & $2(0.8,0.09$ to 2.76$)$ \\
\hline Glaucoma NOS & $1(0.4,0.01$ to 2.13$)$ \\
\hline Halo vision & $2(0.8,0.09$ to 2.76$)$ \\
\hline Iris vascular disorder NOS & $1(0.4,0.01$ to 2.13$)$ \\
\hline Keratitis & $2(0.8,0.09$ to 2.76$)$ \\
\hline Keratoconjunctivitis sicca & $1(0.4,0.01$ to 2.13$)$ \\
\hline Lacrimation increased & $2(0.8,0.09$ to 2.76$)$ \\
\hline Lenticular opacities & $4(1.5,0.42$ to 3.91$)$ \\
\hline Macular degeneration & $2(0.8,0.09$ to 2.76$)$ \\
\hline Macular oedema & $1(0.4,0.01$ to 2.13$)$ \\
\hline Ocular discomfort & $5(1.9,0.63$ to 4.45$)$ \\
\hline Ocular vascular disorder & $2(0.8,0.09$ to 2.76$)$ \\
\hline Papilloedema & $1(0.4,0.01$ to 2.13$)$ \\
\hline Photopsia & $5(1.9,0.63$ to 4.45$)$ \\
\hline Presbyopia & $1(0.4,0.01$ to 2.13$)$ \\
\hline Punctate keratitis & $2(0.8,0.09$ to 2.76$)$ \\
\hline Refractive errors NOS & $4(1.5,0.42$ to 3.91$)$ \\
\hline Retinal exudates & $1(0.4,0.01$ to 2.13$)$ \\
\hline Retinal haemorrhage & $10(3.9,1.87$ to 6.99$)$ \\
\hline Retinal microaneurysms & $1(0.4,0.01$ to 2.13$)$ \\
\hline Retinal pigmentation & $3(1.2,0.24$ to 3.35$)$ \\
\hline
\end{tabular}




\section{Table 8 (continued)}

Adverse event (MedDRA preferred term) Sildenafil $(n=259)$

Retinal tear $2(0.8,0.09$ to 2.76$)$

Vision blurred $21(8.1,5.09$ to 12.13$)$

Visual acuity reduced $3(1.2,0.24$ to 3.35$)$

Visual brightness $4(1.5,0.42$ to 3.91$)$

Visual disturbance NOS

$15(5.8,3.28$ to 9.37$)$

MedDRA=Medical Dictionary for Regulatory Activities; NOS=not otherwise specified. ${ }^{*}$ Counts of adverse events include data up to seven days after last dose of study drug. 


\section{Figure}

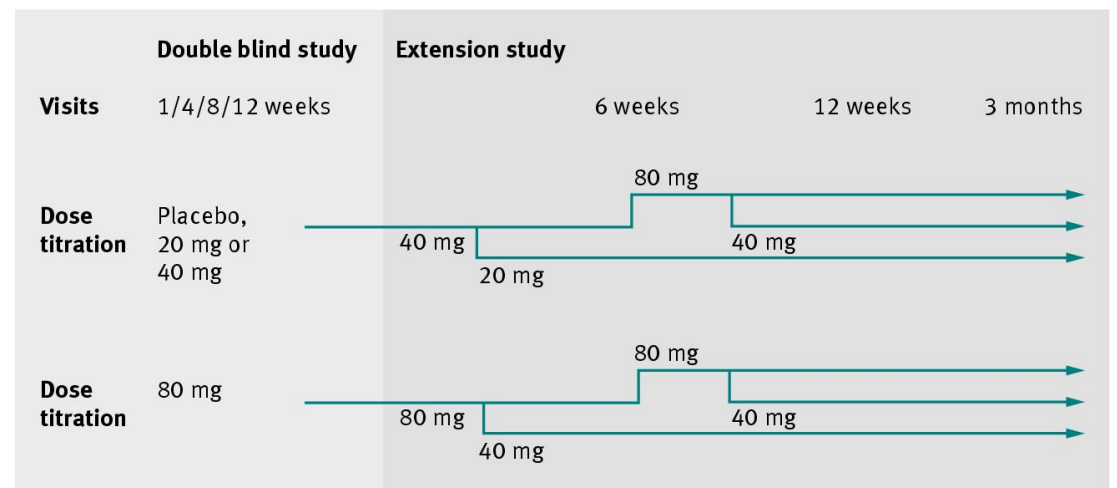

Treatment allocation schedule during open label extension study. During first six weeks, participants who did not tolerate initial sildenafil three times daily dose were allowed to down-titrate to half dose; participants were also allowed to down-titrate once during first 12 weeks 